\title{
Fresh Water Lens Persistence and Root Zone Salinization Hazard Under Temperate Climate
}

\author{
Sija F. Stofberg ${ }^{1}$ • Gualbert H. P. Oude Essink ${ }^{2,3}$ • \\ Pieter S. Pauw ${ }^{1,2}$ • Perry G. B. de Louw ${ }^{2}$. \\ Anton Leijnse $^{1} \cdot$ Sjoerd E. A. T. M. van der Zee ${ }^{1,4}$
}

Received: 16 July 2014 / Accepted: 31 March 2016/

Published online: 11 April 2016

C The Author(s) 2016. This article is published with open access at Springerlink.com

\begin{abstract}
In low lying deltaic areas in temperate climates, groundwater can be brackish to saline at shallow depth, even with a yearly rainfall excess. For primary production in horticulture, agriculture, and terrestrial nature areas, the fresh water availability may be restricted to so-called fresh water lenses: relatively thin pockets of fresh groundwater floating on top of saline groundwater. The persistence of such fresh water lenses, as well as the quantity and quality of surface water is expected to be under pressure due to climate change, as summer droughts may intensify in North-West Europe. Better understanding through modelling of these fresh water resources may help anticipate the impact of salinity on primary production. We use a simple model to determine in which circumstances fresh water lenses may disappear during summer droughts, as that could give rise to enhanced root zone salinity. With a more involved combination of expert judgement and numerical simulations, it is possible to give an appraisal of the hazard that fresh water lenses disappear for the Dutch coastal regions. For such situations, we derive an analytical tool for anticipating the resulting salinization of the root zone, which agrees well with numerical simulations. The provided tools give a basis to quantify which lenses are in hazard of disappearing periodically, as well as an impression in which coastal areas this hazard is largest. Accordingly, these results and the followed procedure may assist water management decisions and prioritization strategies leading to a secure/ robust fresh water supply on a national to regional scale.
\end{abstract}

Sija F. Stofberg

sija.stofberg@wur.nl

1 Soil Physics and Land Management, Wageningen University, P.O. Box 47, 6700 AA Wageningen, The Netherlands

2 Department of Soil and Groundwater, Deltares, P.O. Box 85467, 3508 AL Utrecht, The Netherlands

3 Department of Physical Geography, University of Utrecht, P.O. Box 80125, 3508 TC Utrecht, The Netherlands

4 School of Chemistry, Monash University, Melbourne, VIC 3800, Australia 
Keywords Salinity $\cdot$ Simple model $\cdot$ Fresh water lens $\cdot$ Root zone salinization

\section{Introduction}

Soil and groundwater salinity have long been recognized as major problems for crop production worldwide (Maas and Hoffman 1977; Tanji and Kielen 2002; Rozema and Flowers 2008). Whereas it may be most pressing in semi-arid regions (Allison (1964) mentions one third of agricultural land in arid and semi-arid regions), in temperate regions, salinity may cause problems as well (De Louw et al. 2013; Vandenbohede et al. 2014). Commonly, this is due to elevated salinity by seawater intrusion via groundwater or surface water, but it may also be significant by salt spray near the coast or by de-icing roads (Thunqvist 2004). Due to climate change, the area that may be salt affected can increase. For temperate regions, particularly more frequent droughts may enhance salt stress in the growing season (KNMI 2014).

Plants exposed to elevated salinity may experience different forms of stress. Due to the high osmotic value of saline solutions, soil water may become less available for plants to accommodate their transpiration and primary production (de Wit 1958; Maas and Hoffman 1977) in a similar way as drought. However, it is also well known that salts (e.g. involving $\mathrm{Na}^{+}, \mathrm{Cl}^{-}$) may be toxic for plants, or that toxic components such as boron (B) and selenium (Se) become more bio-available under saline conditions. In addition, induced nutrient deficiency has been well documented, e.g. for iron and nitrate (Schinas and Rowell 1977; Grattan and Grieve 1992). Salt tolerance has been investigated much for agricultural crops, both in field and greenhouse conditions, and particularly for the case that salts enter the root zone. Different plant species have different salt tolerances and strategies to deal with salinity (Parida and Das 2005; Munns and Tester 2008).

Because of the long awareness of the impact of salinity on primary production, research of salt affected soils has a long tradition. Two main routes for salts entering the root zone are (i) capillary rise from brackish to saline groundwater leading to primary salinization, and (ii) salt spray and irrigation causing secondary salinization (Szabolcs 1989). For the case of secondary salinization, an important model concept has been developed, called the Leaching Requirement (Richards et al. 1954) and that is aimed at preventing too large salt concentrations in the root zone.

For temperate regions, where annual precipitation is usually sufficient for plant transpiration demands, infiltrating water can meet upward seeping groundwater, if the soil surface is close to the drainage level. In that case, the so-called fresh water lenses that develop on top of brackish or saline groundwater in coastal areas may become rather thin (Eeman et al. 2011; De Louw et al. 2011). If these lenses temporarily disappear in summer, this may lead to saline capillary rise water, that salinizes the root zone.

Avoiding, mitigating or adapting to the adverse effects of groundwater salinity is possible if we recognize in which cases salts accumulate in the root zone. In this paper, we consider the hazard of root zone salinization due to depletion of fresh water lenses, as in that case, capillary rise of saline water to the root zone commences. We provide relatively simple tools that differ with respect to their data demand, to appraise this hazard.

\section{Fresh Water Lens Persistence}

In low lying regions with shallow saline groundwater, such as in deltaic areas or small islands, saline water may enter the root zone due to capillary upward flow of groundwater. In case the 
annual rainfall is sufficient, precious fresh water lenses may develop preventing the underlying saline groundwater to reach the root zone via capillary rise. Experimental evidence of fresh water lenses on saline groundwater has been provided for different continents, e.g. De Louw et al. (2011), Fetter (1972), Underwood et al. (1992), even for inland areas of Australia (Jolly et al. 1998; Cendón et al. 2010), Oman (Young et al. 2004) and Hungary (Szabolcs 1989; Toth 2008). Whether or not a fresh water lens protects primary production from salt induced yield depressions will depend on the persistence of such lenses in temperate climates in the dry season (often summer).

Fresh water lenses resemble large fresh water volumes in coastal dune areas (Martinez and Psuty 2008) and analytical solutions have been found for different assumptions regarding e.g. the outflow zone at the dunes' perifery, or whether or not the salt underlying water is flowing, assuming a sharp fresh/salt interface (Badon-Ghijben 1888; Herzberg 1901; Van Der Veer 1977; Maas 2007). Investigating fresh water lenses in low-lying flat coastal regions, Eeman et al. (2011) revealed that the analytical solution provided by Maas (2007) is in close agreement with their numerical modelling using the model SUTRA-3D. The solution of Maas is given by:

$$
\sqrt{\frac{Z^{2}}{\left(L^{2}+Z^{2}\right)}}=\left[-\frac{S}{P}+\sqrt{\left(\frac{S}{P}\right)^{2}+4\left(1+\frac{S}{P}+R\right)}\right] /\left[2\left(1+\frac{S}{P}+R\right)\right]
$$

where $S$ is upward seepage rate $\left[\mathrm{LT}^{-1}\right], P$ is mean net precipitation or infiltration rate [LT $\left.{ }^{-1}\right], R$ is the Rayleigh number $\left(R=\kappa g \Delta \rho /(\mu P)\right.$ with intrinsic permeability $\kappa\left[\mathrm{L}^{2}\right]$, gravity acceleration $g\left[\mathrm{LT}^{-2}\right]$, density difference $\Delta \rho\left[\mathrm{M} / \mathrm{L}^{3}\right]$, and dynamic viscosity $\mu\left[\mathrm{ML}^{-1} \mathrm{~T}^{-1}\right], L$ is the half spacing [L] between two drains or ditches, i.e., the distance from drain or ditch to hydrological divide, and $Z$ is the largest thickness of the lens at the hydrological divide. For such a lens, the volume $V_{M}\left[\mathrm{~L}^{3}\right]$ is equal to

$$
V_{M}=\frac{1}{4} \pi L Z
$$

The impact for upward seepage $S$ in (1) is a crucial one, as it is a major force that counters the development of a full Badon-Ghijben-Herzberg (BGH) lens that complies with Archimedes' law. Especially this occurs for low lying areas in e.g. delta regions, as in Dutch polders (De Louw et al. 2011, 2013) or the Po delta, Italy (Vandenbohede et al. 2014). In the absence of such seepage, other (simpler) solutions are available that are outside the scope of this paper, as here we are focusing on lowland areas with upward saline seepage rather than coastal dunes, where groundwater flow is predominantly downward and BGH lens thicknesses of tens of meters can develop.

For the case that the groundwater densities of the lens and the underlying groundwater are equal, the solution follows directly from (1) by setting the Rayleigh number equal to zero, giving for the right hand side $(1+S / P)^{-1}$. Such a situation is often found in topographically higher areas with upwelling fresh groundwater as in stream valleys (Cirkel et al. 2014). Then, lens thickness thicker than those for sea water salinity circumstances are found. From (1), we then obtain for any value of $R$, an expression for Z:

$$
Z=\sqrt{ }\left(L^{2}\left[\frac{F^{2}}{1-F^{2}}\right]\right) ; F=\left\{-m+\sqrt{m^{2}+4 r}\right\} / 2 r ; m=\frac{S}{P} ; r=1+m+R
$$


Impressions of lens properties are given for different parameter combinations in Fig. 1 for a seepage/recharge ratio $S / P=1$, and a permeability $\mathrm{K}=10^{-12} \mathrm{~m}^{2}$ which is equivalent to a hydraulic conductivity of about $1 \mathrm{~m} /$ day $(K=\kappa \rho g / \mu)$. Lens thickness $Z$ is proportional to the half distance between drains or ditches $L$ and increases as the water density $\Delta \rho$ differences between lens and groundwater become smaller in agreement with a BGH lens.

Recognizing that both the lens thickness and the mixing zone thickness are important for the risk that brackish water from the mixing zone moves up by capillary rise into the root zone,
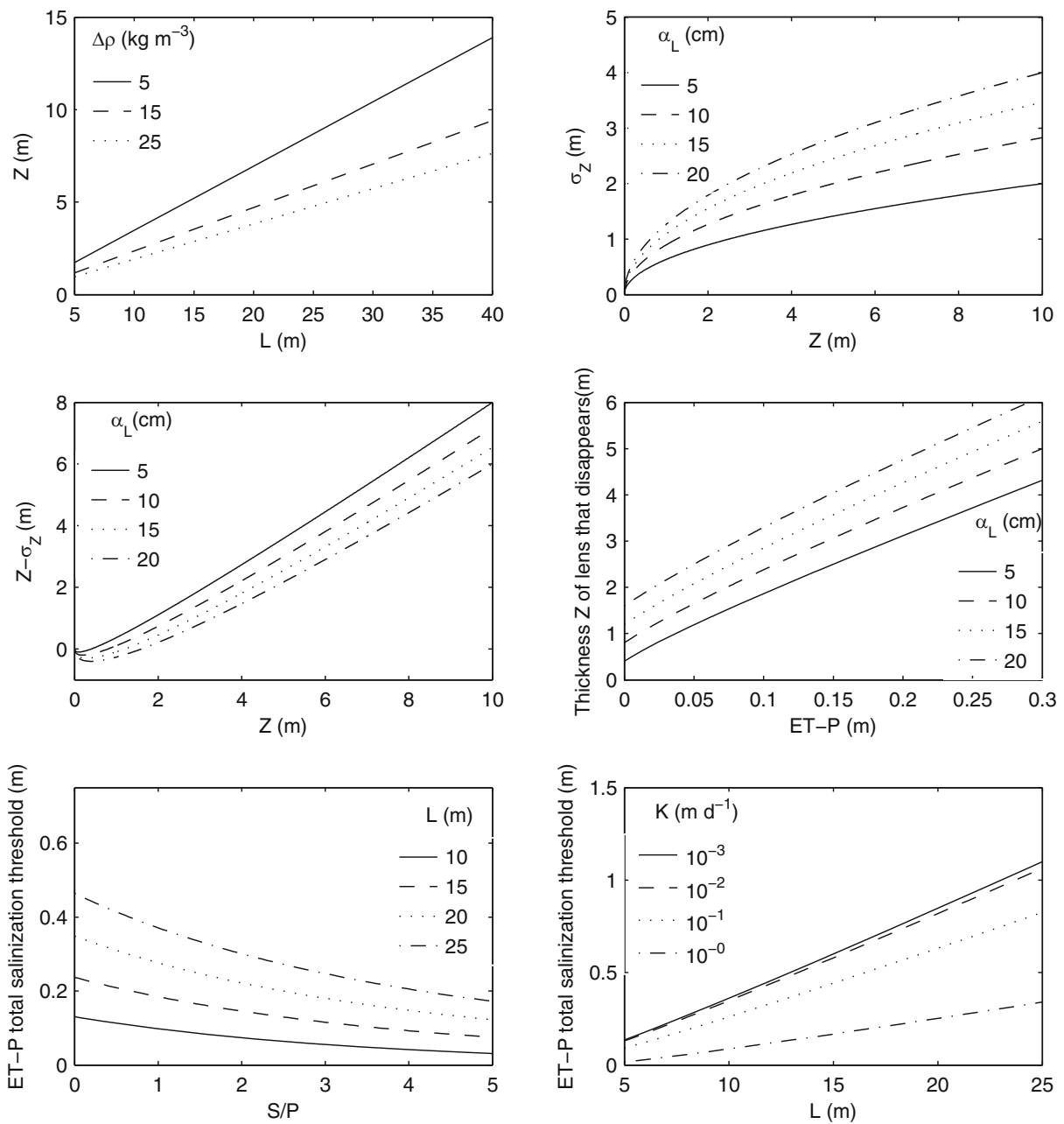

Fig. 1 Lens properties as a function of system parameters: a Lens thickness $Z$ as a function of half spacing between drains or ditches $L$ for several water density $\Delta \rho$ differences between lens and groundwater, seepage/ recharge ratio $\mathrm{S} / \mathrm{P}=1, \mathrm{k}=10^{-12} \mathrm{~m}^{2}$. b Mixing zone thickness $\sigma_{\mathrm{Z}}$ as a function of lens thickness for different longitudinal dispersivity values $\alpha_{L}$. c Thickness of fresh water zone $Z-\sigma_{Z}$ as a function of $Z$ for different longitudinal dispersivity values. $\mathbf{d}$ Thickness of lens $Z$ that may disappear as a function of rainfall deficit ET-P for different longitudinal dispersivity values, specific yield $s_{y}=0.1$. e Threshold rainfall/precipitation deficit at which the total fresh water zone disappears as a function of seepage/recharge ratio for different half distances between ditches, a density difference as found in Dutch coastal subsoils of $\Delta \rho=15 \mathrm{~kg} \mathrm{~m}^{-3}, \mathrm{k}=10^{-12} \mathrm{~m}^{2}, \alpha_{L}=0.1 \mathrm{~m}$, $\mathrm{s}_{\mathrm{y}}=0.1$. $\mathbf{f}$ Threshold rainfall deficit at which the total fresh water zone disappears as a function of half distance between ditches, for different values of hydraulic conductivity, $\mathrm{S} / \mathrm{P}=1, \Delta \rho=15 \mathrm{~kg} \mathrm{~m}^{-3}, \alpha_{L}=0.1 \mathrm{~m}, \mathrm{~s}_{\mathrm{y}}=0.1$ 
an alternative to numerically estimating the critical mixing zone thickness is appealing. Based on the analysis of Cirkel et al. (2015) this thickness can be estimated easily. We consider a lens of thickness $Z$ where half of the mixing zone is situated in the lens, and the other half is in the saline groundwater below the lens.

This half thickness $\left(\sigma_{Z}\right)$ can also be represented by the variance or second central spatial moment of vertical salt concentration change

$$
\sigma_{z}^{2}=2 \alpha_{L}\left\langle\left|v_{z}\right|\right\rangle t
$$

In (4), $\alpha_{L}$ is the longitudinal dispersivity $\left[\mathrm{L}^{2}\right]$ and in view of recent insights by Eeman et al. (2012) and Cirkel et al. (2015), we may interpret $\left\langle\left|v_{z}\right|\right\rangle t$ as the total distance that the mixing zone travels during one year (lens growing in winter, diminishing in summer). If the lens disappears at the end of each drought period and the fluctuation of the mixing zone is sinusoidal, the amplitude of vertical transition zone position is equal to $A z=Z$. This leads to $\left\langle\left|v_{z}\right|\right\rangle=4 A_{z} f$ where $f$ is the seasonal frequency. We then obtain from (4)

$$
\sigma_{z}=\sqrt{8 \alpha_{L} A_{z}}=\sqrt{8 \alpha_{L} Z}
$$

In Fig. 1b we show how $\sigma_{Z}$ increases as a function of lens thickness if the longitudinal dispersivity $\alpha_{L}$ increases. As these figures show, for relatively thin lenses, their thickness can be of the same order of magnitude as that of the mixing zone, which means that the water lens contains significant amounts of salts. This is also seen from the thickness of fresh water zone, when the mixing zone thickness within the lens, $\sigma_{Z}$, is subtracted from the lens thickness Z. In Fig. $1 \mathrm{c}, Z-\sigma_{Z}$ is shown as a function of $Z$ and for different longitudinal dispersivities. For thin lenses, the lens may become brackish throughout, as is implied by the negative values of $Z-\sigma_{Z}$. This was also found by field measurements in the south-western Dutch delta which showed that almost all rainwater lenses lacked truly fresh water (De Louw et al. 2011). Since the lens thickness represents a volume of water, it is possible to assess for which thicknesses of the lens it will disappear as a function of rainfall deficit ET-P, longitudinal dispersivity $\alpha_{L}$, and specific yield $s_{y}$ (taken to be 0.1 ). For the Netherlands, a cumulative rainfall deficit of $200 \mathrm{~mm}$ is not uncommon, hence, lenses of 3-4 m thickness may disappear to such a degree, that brackish water can reach the root zone by capillary rise. With this in mind, we show in Fig. 1e, how the rainfall deficit for which the lens disappears will depend on the distance $L$ between drain and middle of the field, and the ratio of seepage and recharge ( $S / P$, see Eq. 1). It is clear, that for the chosen parameters and a reasonable rainfall deficit, this is mostly the case for small fields and relatively large seepage rates. Underlying reason is that stronger upward groundwater seepage $(S)$ forces the interface between fresh and salt water upwards, i.e., leads to small $Z$-values. Such a combination may represent a wetland under native vegetation rather than an agricultural field. If, however, predictions for a substantial sea water level rise become true, this inevitably causes an increase in upward seepage (Oude Essink et al. 2010).

A factor that is somewhat hidden in the illustrations is the soil type. This can be illustrated with Fig. $1 \mathrm{f}$ that shows how the rainfall deficit, where the lens disappears, depends on both half spacing $(L)$ and the soil hydraulic conductivity. Realistic values may be reached with high hydraulic conductivities or small $L$-values. In practice, ditch distances depend on the hydraulic conductivity of the soil, with smaller conductivities meaning smaller L-values, but also on desired drainage levels. In Fig. 2, the lenses are shown for a clayey and for a peaty soil. Despite its larger conductivity, fields in peat soil are often more densely drained, in order to more accurately fix groundwater levels. If groundwater levels were allowed to fall significantly in 

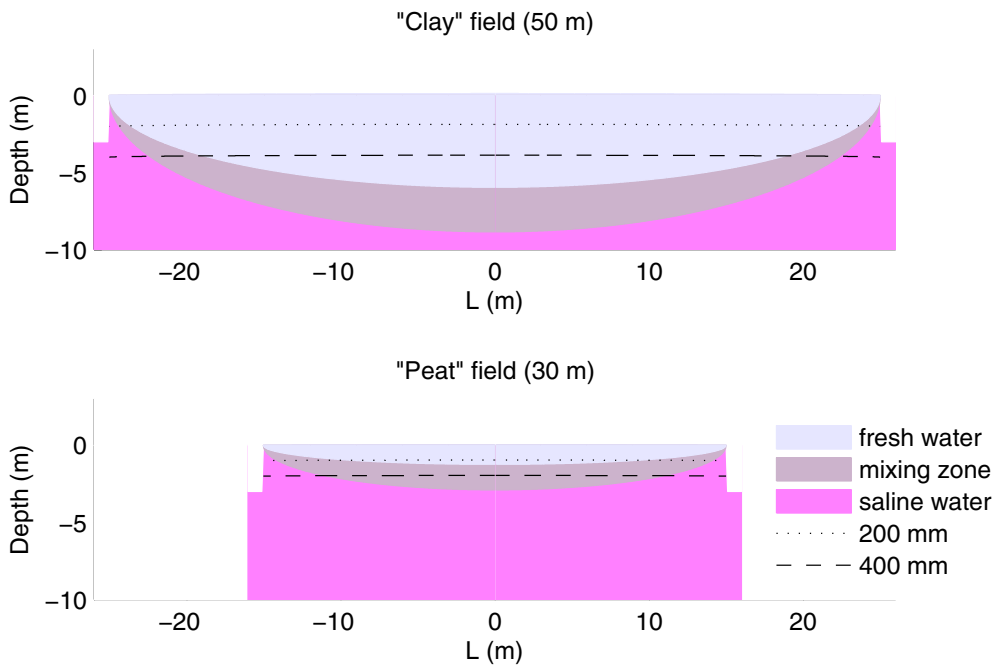

Fig. 2 Cross section of a fresh water lens in a large 'clay' field with low hydraulic conductivity $(\mathrm{L}=25 \mathrm{~m}$, $\left.\mathrm{K}=0.01 \mathrm{~m} \mathrm{~d}-1, \mathrm{~s}_{\mathrm{y}}=0.1\right)$ and a smaller 'peat' field with higher hydraulic conductivity $(\mathrm{L}=15 \mathrm{~m}, \mathrm{~K}=1 \mathrm{~m} \mathrm{~d}-1$, $\left.\mathrm{S}_{\mathrm{y}}=0.2\right)$ in a situation in which $\mathrm{S} / \mathrm{P}=2, \Delta \rho=15 \mathrm{~kg} / \mathrm{m}^{3}$ and $\alpha_{L}=0.12 \mathrm{~m}$. Dotted lines indicate which part may be depleted if the rainfall deficit increases to 200 and $400 \mathrm{~mm}$. Percentage of the field that is depleted of fresh water due to rainfall deficit is $6 \%(200 \mathrm{~mm})$ and $25 \%(400 \mathrm{~mm})$ in the clay field and $38 \%(200 \mathrm{~mm})$ and $100 \%$ $(400 \mathrm{~mm})$ in the peat field

peat, this might lead to mineralization of peat, irreversible consolidation and land subsidence. As Fig. 2 shows, good control of groundwater level by intense drainage results in a thin and vulnerable fresh water lens. In our calculations it has not been taken into account that soil type may affect net infiltration, as larger hydraulic conductivities favour a large net infiltration rate, hence thicker fresh water lenses (De Louw et al. 2011). This may mean that in practice, the total salinization threshold differences between different soil types are slightly smaller than represented in Fig. 1f.

With results as in Fig. 1, it is also easy to see what the risk is that a lens will disappear completely during a dry period if we consider climate change projections. In the next decades, the average rainfall deficit in summer may increase from 144 to $187 \mathrm{~mm}$ in 2050, with 10-year extremes of $288 \mathrm{~mm}$ (KNMI 2014). This implies that lenses with a thickness of $0.25 \mathrm{~m} /$ $s_{y}=2.5 \mathrm{~m}$ (for our default parameter values) may regularly disappear. A record dry year was 1976, in which the rainfall deficit grew to $360 \mathrm{~mm}$, and for a specific yield of 0.1 , even lenses of $3.6 \mathrm{~m}$ thick might disappear.

The approximations of Fig. 1 are somewhat crude, because under water and salt stress, plants will cease to transpire at the potential rate. At which concentrations salt stress occurs depends on both crop and genotype. Also regarding evaporation from the bare soil surface, it is unlikely to continue at maximum rate as drought sets in. Instead, a drying front may cause a rapid decline of evaporation as soil dries out. In addition, water that flows upward from the declining fresh water lens towards the root zone will take time to travel that distance. This time is important in view of the frequency with which significant rainfall occurs, as such showers may leach salt that is underway. In other words, characteristic times of rainfall and water travel times between saturated groundwater and root zone become important. This is even more so the case if cumulative effects over years can be anticipated, e.g. due to summers that become drier due to climate change. For instance, a rainfall deficit requires time to be balanced by a 
rainfall excess, yet during this time, discharge to drains and ditches continues to remove fresh water. Accordingly, the risk of a succession of different dry summers is probably a factor to be accounted for.

Although simplifications have been made on the reaction of fresh water lenses to erratic rainfall, this is not the case with regard to the impact of erratic rainfall on the fresh/salt mixing zone. High frequency variations of lens recharge may affect the thickness of the lens and therefore the value of $Z$, but these variations do not affect the validity of (4) and (5), as was demonstrated (Cirkel et al. 2014).

\section{Regionalization of Fresh Water Persistence}

The tools that were discussed in the previous section are based on analytical approximations that can be easily communicated. However, for management it is often attractive to present dependencies between environmental conditions and output of interest in the form of maps, as done by De Louw et al. (2011, 2013). With various numerical instruments, we made such a vulnerability map for regions with saline or brackish groundwater in The Netherlands.

The vulnerability map was inferred from the chloride concentration below the upper confining layer in the Netherlands (Oude Essink et al. 2010; De Lange et al. 2014). This data was retrieved from numerical models at the regional/national scale of the Netherlands (De Lange et al. 2014), with which future stresses were simulated. Comparing the results of this exercise with field data from for example De Louw et al. (2011) yielded acceptable results, except in the polder areas which used to be inland lakes and that were reclaimed relatively recently (i.e., later than $1800 \mathrm{AD}$ ). In these areas, this approach underestimated the thickness of the freshwater lenses. Therefore, a paleogeographical map (Vos 2015) was used to delineate these 'recently' reclaimed polders and to assign them to the 'Low' class. The year 2000 was compared with 2100, to indicate the effect of future stresses, such as land subsidence (Haasnoot et al. 1999), climate change and sea level rise.

Figure 3 shows the vulnerability of shallow fresh water lenses, for the current situation as well as for the situation in year $2100 \mathrm{AD}$. For the year $2100 \mathrm{AD}$, climate change impacts on the chloride concentration below the upper confining layer were implemented using results of national groundwater flow model simulating effects due to sea level rise, changes in precipitation patterns and autonomous salinization (Oude Essink et al. 2010; De Lange et al. 2014). Land subsidence was incorporated using the map of Haasnoot et al. (1999) in the expert judgement analysis. Because this approach is in some aspects fuzzy, the results of the final maps should be used with care. On the other hand, this exercise does show how with limited time but with distributed data used in numerical models, a reasonable indication of the vulnerability of fresh water lenses can be obtained. A profound advantage is also, that parameters that co-vary (e.g. $L$ and $K$ in Fig. 1f) are considered in their mutual dependency. Results as Fig. 3 can then be used by water authorities and policy makers as first-step decision information.

\section{Modelling Root Zone}

As is already apparent from the previous sections, changes of precipitation and evapotranspiration affect the salinity of the shallowest groundwater that may enter the root 

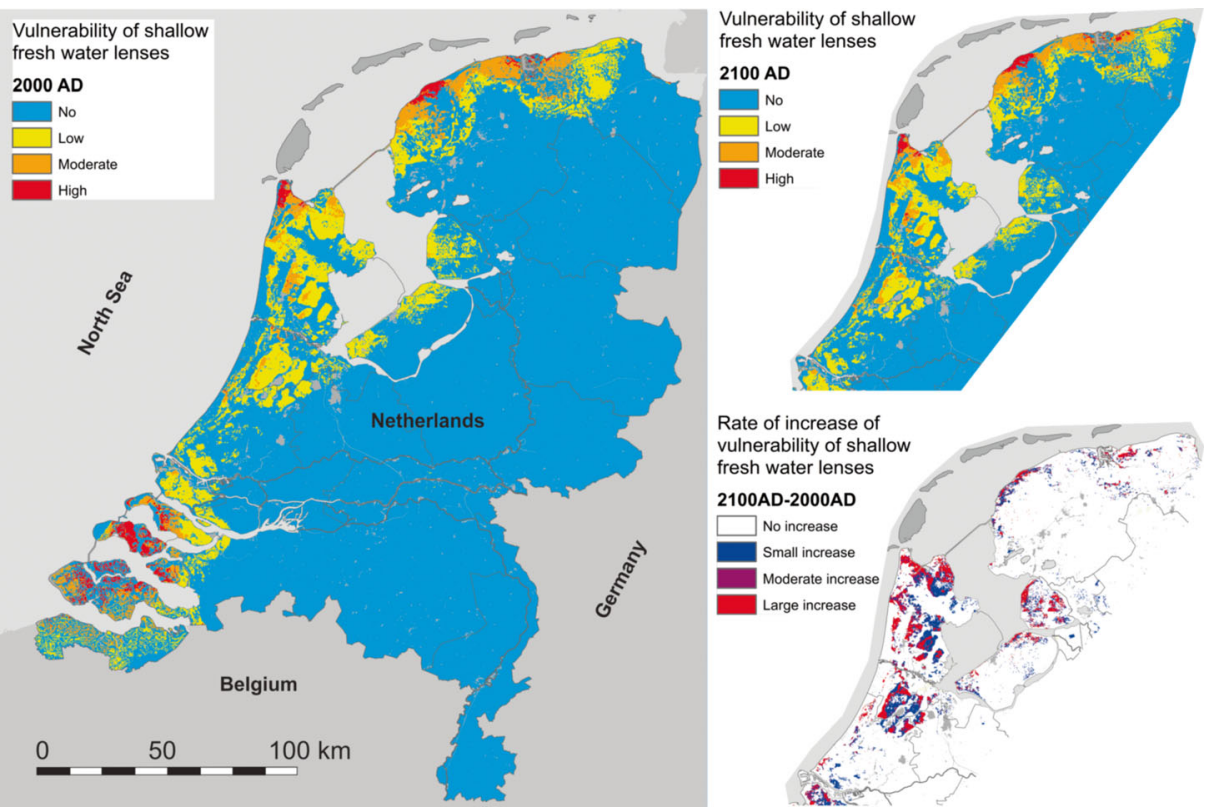

Fig. 3 Vulnerability of shallow fresh water lenses in the Dutch coastal zone, on 2000 AD and 2100 AD, as well as the rate of increase of the vulnerability of the fresh water lenses over this $2000 \mathrm{AD}-2100 \mathrm{AD}$ period, all based on a national numerical model and expert judgement. The vulnerability classes 'No', 'Low', 'Moderate', and 'High' correspond with chloride concentrations below the upper confining layer of $\mathrm{Cl}^{-}=0 \mathrm{mg} \mathrm{l}^{-1}, 0 \mathrm{mg} \mathrm{l}^{-1}>\mathrm{Cl}^{-}$ $<1000 \mathrm{mg} \mathrm{l}^{-1}, 1000 \mathrm{mg} \mathrm{l}^{-1}>\mathrm{Cl}^{-}<5000 \mathrm{mg} \mathrm{l}^{-1}$, and $\mathrm{Cl}^{-}>5000 \mathrm{mg} \mathrm{l}^{-1}$

zone by capillary rise if fresh water lenses disappear temporarily. This may introduce salts into the root zone. Though salinity has been investigated already for a long time (Richards et al. 1954; Bresler et al. 1982), the impact of erratic weather has not often been the focus.

Practically, a major problem is that weather can be predicted in a statistical sense (mean temperature, long term average rainfall), but actual weather may differ significantly from the average behaviour and is hardly predictable. It is nearly impossible to predict whether a year will be average, or dry or wet. However, for e.g. farmers and water managers, this type of information is crucial. For practice, it is important to deal with erratic weather, as it affects e.g. primary production (yield) and it is necessary to recognize the risk of crop failure.

To model soil, which is implied in predicting, the basis is usually the Richards' equation (for unsaturated water flow, see e.g. Kuhlmann et al. 2012) and the convection dispersion or CDE equation for salt transport. Despite improving hardware and data availability, combining these equations with e.g. GCM modelling of climate change is still a challenge. This is much less the case with the popular, though simplified, root zone 'bucket' approach, in which the root zone is assumed to be a perfectly homogenized (ploughed) soil layer (Rodriguez-Iturbe and Porporato 2004).

Adopting this latter approach, taking into account the capillary upward flow from groundwater (Vervoort and van der Zee 2008), the salt balance has been solved for the long term by Shah et al. (2011). Recently, this numerical analysis has been extended towards sodicity, which considers the relative accumulation of sodium in soil to levels where it may induce soil 
structure degradation (Bresler et al. 1982; van der Zee et al. 2014). Although soil sodicity is a long term threat to sustainable soil use because it is poorly reversible, we will not address this process in detail in this paper, to avoid duplication with the recent analysis using the model SODIC by van der Zee et al. (2014).

Due to the irregular rainfall and seasonal evapotranspiration, the root zone has periods of drought and of wetness. During drought, capillary rise of groundwater may replenish the root zone, while during wet periods, root zone water above the field capacity may readily drain. For different conditions, Shah et al. (2011) investigated how salt accumulates in the root zone if the groundwater is somewhat brackish. Likewise, Suweis et al. (2010) considered the situation where salt spray supplies salts to the root zone.

To give an impression of the impact of weather on salinity, we simulated water and salt balances. To efficiently simulate the water and salt balances, we adopted the approach of Vervoort and van der Zee (2008) and Shah et al. (2011), where a root zone was considered at some distance above the water table. Though the Netherlands are characterized by sufficient rainfall of about $800 \mathrm{~mm} / \mathrm{y}$, net recharge has a distinct seasonal variation, as evapotranspiration is mainly concentrated in the summer period. On average, net groundwater recharge is less than $1 \mathrm{~mm} / \mathrm{d}$.

For Dutch conditions, it is quite well possible that groundwater at the water table is brackish, e.g. if fresh water lenses disappear in summer (De Louw et al. 2011, 2013). We considered a soil that initially is not saline. Due to alternation of rainfall and irrigation water entering the soil and of capillary rise of groundwater, the root zone will salinize to some degree. As demonstrated in earlier work (Suweis et al. 2010; Shah et al. 2011), this leads to irregular fluctuations of salt concentration (C) that builds up first and then stabilizes around a long term mean value. The resulting strongly erratic pattern of $\mathrm{C}$ as a function of time, is a direct consequence of the erratic pattern of rainfall, irrigation, and other water balance terms. Therefore, this pattern as such is not tractable to real prediction. In a first assessment, it may be sufficient to assess the mean concentration around which $\mathrm{C}$ will vary through time, for comparison with the crop's tolerance. Such a first assessment was already developed much earlier (Richards et al. 1954), for the case that salts originate from brackish irrigation water. As its main concept, it used the so-called leaching requirement $(L R)$ given by

$$
L R=\frac{D_{d w}}{D_{i r r}}=\frac{\theta_{f c}}{\theta_{s p}} \cdot \frac{C_{i r r}}{C_{e}}
$$

written in terms of concentrations, instead of electrical conductivity as often used. In Eq. (6), $D$ is the quantity (in water layer thickness per year) of irrigation water applied (irr) and drainage water $\left({ }_{\mathrm{dw}}\right), C$ refers to the concentration of salts in irrigation water and in the saturated paste of soil (subscript ${ }_{e}$ ), and $\theta_{s p}$ and $\theta_{f c}$ are the volumetric water contents of the saturated paste and at field capacity $(\mathrm{pF}=2.5)$, respectively, and correspond with the water contents at the point of liquefaction and above which water drains due to gravity (Richards et al. 1954). The principle is that if the tolerance of a crop for salt is designated as $C_{e}$, then the leaching requirement tells us how much irrigation water excess for drainage is needed, to keep concentrations in this soil at this tolerance threshold. $L R$ is attractive, as it gives a simple and robust tool to predict salinity due to irrigation with water that contains some salts, in other words, it is simple tool to assess irrigation practise sustainability. 
It is attractive to develop a similarly robust tool to predict salinity if salts originate from capillary upward flowing groundwater and erratic weather. Shah et al. (2011) investigated the long term salinity for a range of conditions, using the approach that has just been described. Using the same model SODIC, that was extended to account for sodicity, but for Dutch conditions, the long term average salt concentration was simulated numerically. It appeared that in its simplest form, if only groundwater is a source of salts, the long term root zone salinity can be estimated with

$$
\langle C\rangle=\frac{\left\langle D_{c r}\right\rangle}{\left\langle D_{d w}\right\rangle} C_{Z}
$$

where brackets $<$. $>$ denote time-average, $D_{c r}$ stands for capillary rise flux of groundwater, $D_{d w}$ is the drainage water flux, and the phreatic groundwater concentration is $C_{z}$.

In many agricultural regions, besides precipitation, both groundwater and irrigation water are used for evapotranspiration. Therefore, we take the result of Shah et al. (2011) as a point of departure to consider the case where irrigation water has a distinct salt concentration $C_{i r}$, but also groundwater is (somewhat) saline. We consider a clayey soil covered with grass, with different groundwater levels below soil surface $\left(Z_{f}\right)$ in the range $100 \mathrm{~cm}<Z_{f}<250 \mathrm{~cm}$ and a root zone thickness of $25 \mathrm{~cm}$. By using the reasoning that resulted in (7), we obtain in analogy the following result

$$
\langle C\rangle=\frac{\left\langle D_{c r}\right\rangle C_{Z}+\left\langle D_{i w}\right\rangle C_{i r r}}{\left\langle D_{d w}\right\rangle}
$$

This expression, that ignores short term fluctuations, agrees quite well with numerical results, and only has a small systematic bias as can be seen from Fig. 4.

Figure 5 illustrates the long-time average salt concentrations under various Dutch conditions as calculated with Eq. 8, assuming capillary rise of (moderately) saline groundwater after (partial) disappearance of a fresh water lens. Average salt concentrations do not exceed groundwater concentrations due to dilution (precipitation surplus, Fig. 5a), although in practice, the concentrations would vary seasonally. The salinizing effects of capillary rise (during seasonal precipitation deficit, assuming no reduction of evapotranspiration) may be mitigated by irrigating with water that has a lower salt concentration than the average concentration that would have occurred without irrigation (Fig. 5b, d and e). Moreover, it should be noted that irrigation lead to decreased capillary rise as well, adding to the mitigating effect. If however, the concentration of irrigation water is equal to the

Fig. 4 Root zone salt concentrations as modelled numerically for a root zone model, and as determined with the approximation of Eq. (8), for different groundwater levels $\left(Z_{f}\right.$ in $\mathrm{cm}$ below surface) indicated by the colour bar to the right, and a temperate climate as in The Netherlands. Irrigation water salinity given by $C_{i r r}$ in $\mathrm{mol}^{-1}$, and groundwater salt concentration of $0.02 \mathrm{~mol} \mathrm{l}^{-1}$

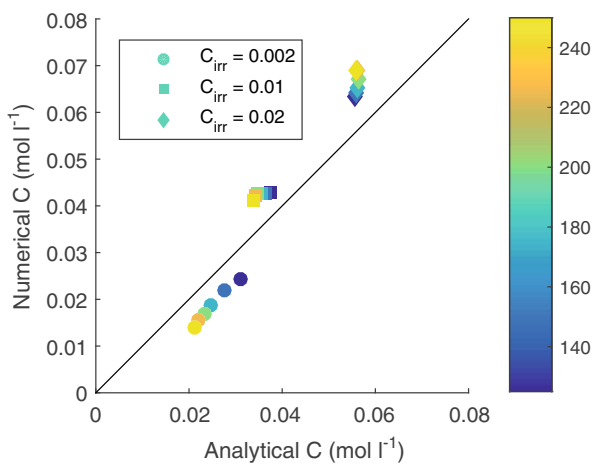



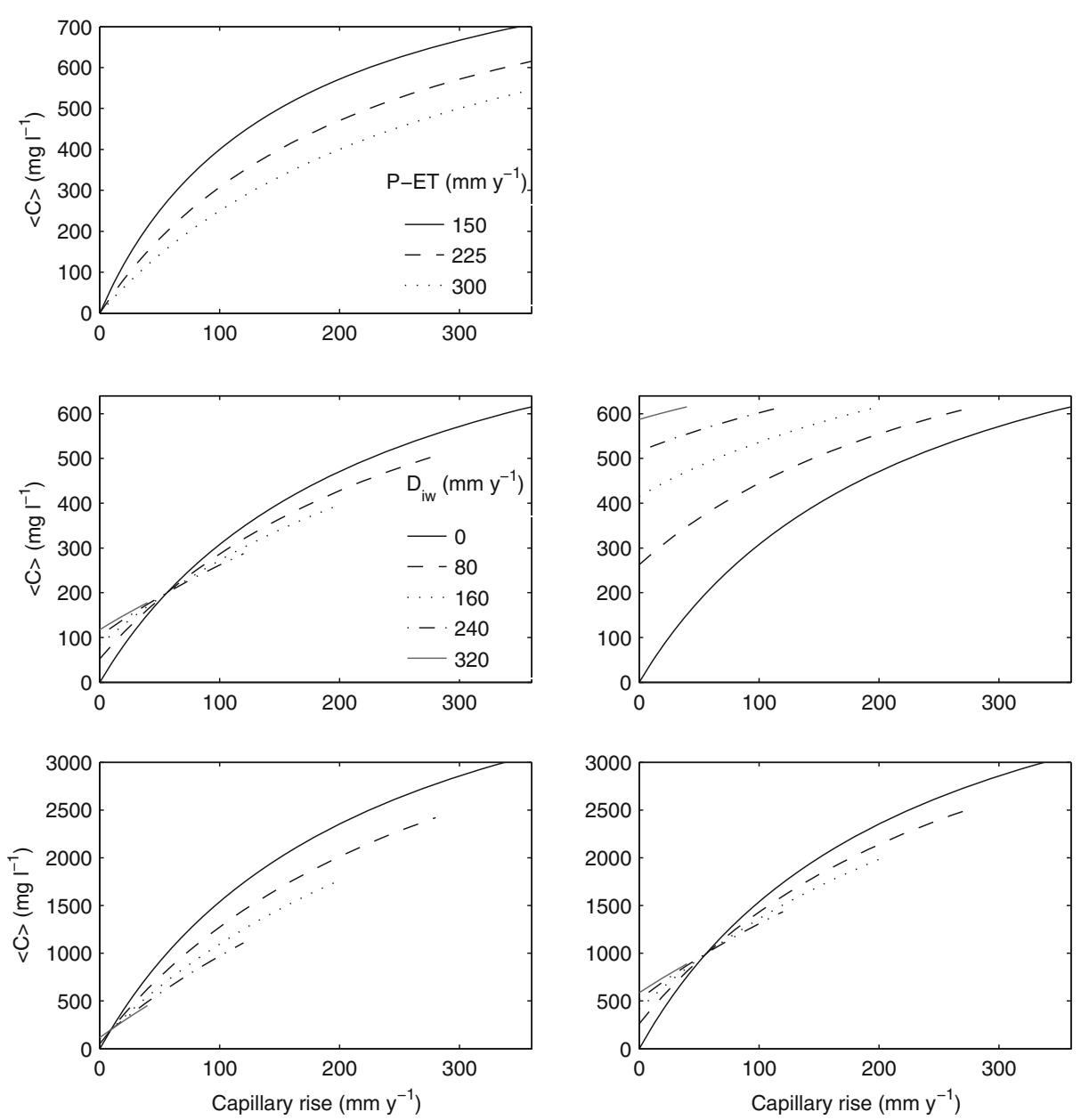

Fig. 5 Average salt concentrations as calculated by Eq. 8. Drainage $\left(D_{d w}\right)$ is calculated as the sum of the precipitation surplus (P-ET), capillary rise $\left(\mathrm{D}_{\mathrm{cr}}\right)$ and irrigation $\left(\mathrm{D}_{\text {irr }}\right)$. a The effect of precipitation surplus on the average salt concentration as a function of capillary rise, in a situation without irrigation and a groundwater chloride concentration of $1000 \mathrm{mg} \mathrm{l}^{-1}$. b-e show the effect of irrigation on the average chloride concentration as a function of capillary rise. A precipitation surplus of $225 \mathrm{~mm} \mathrm{y}^{-1}$ is assumed and the sum of irrigation and capillary rise is assumed to not exceed $360 \mathrm{~mm} \mathrm{y}^{-1}$. b Average chloride concentration with a groundwater salinity of $1000 \mathrm{mg} \mathrm{l}^{-1} \mathrm{Cl}^{-}$and irrigation water salinity of $200 \mathrm{mg} \mathrm{l}^{-1} \mathrm{Cl}^{-}$. $\mathbf{c}$ Average salt concentration with a groundwater salinity of $1000 \mathrm{mg} \mathrm{l}^{-1} \mathrm{Cl}^{-}$and irrigation water salinity of $1000 \mathrm{mg} \mathrm{l}^{-1} \mathrm{Cl}^{-}$. d Average salt concentration with a groundwater salinity of $5000 \mathrm{mg} \mathrm{l}^{-1} \mathrm{Cl}^{-}$and irrigation water salinity of $200 \mathrm{mg} \mathrm{l}^{-1} \mathrm{Cl}^{-}$. e Average salt concentration with a groundwater salinity of $5000 \mathrm{mg} \mathrm{l}^{-1} \mathrm{Cl}^{-}$and irrigation water salinity of $1000 \mathrm{mg} \mathrm{l}^{-1} \mathrm{Cl}^{-}$

groundwater salinity, irrigation leads to increased long-term average concentrations (Fig. 5c).

More refined predictions of long term root zone concentrations can be made, based on projected future rainfall intensities and evapotranspiration demand. At this moment, it is not yet clear whether such predictions have to account for the travel time of capillary upward moving water and salt, and the probability that saline water is leached before it reaches the root zone, by incidental rainfall showers. 


\section{Summary and Conclusions}

In managing fresh water scarcity and salinity in the deltaic areas, which may grow in importance due to climate change and related sea level rise, modelling of the behaviour of shallow fresh water lenses in relation to increased root zone salinities is an important tool to help us anticipate possible chances in primary food production. To be of use, models have to be aligned with experimental results, i.e., be properly parameterized. A main issue is that a proper assessment must be made of how crops respond to salinity. Despite that this has been under investigation for decades, quite basic issues such as compensation behaviour of plants in dealing with drought and salt stress are still frontiers in our science (Javaux et al. 2008; Kuhlmann et al. 2012).

Despite the recognition of scientific gaps in knowledge, for managing our resources, a robust prediction of broad features may be sufficient these coming decades. An example is given by predicting the persistency of fresh water lenses in saline, shallow groundwater situations such as in deltaic areas. Numerical modelling by Eeman et al. (2011, 2012) revealed that analytical solutions of e.g. Maas (2007) describe the mean depth of the fresh/salt transition zone pretty well. With some approximations that are also founded on a good agreement with numerical simulations, we can judge also the thickness of the fresh water lens above the fresh/salt transition zone. In combination, this resulted in an assessment of the combination of factors for which fresh water lenses may disappear in drier summers as predicted for climate change on the European subcontinent. It appears that in practice, fresh water lenses have to be very thin or subject to large mixing at the interface to be threatened to disappear completely. However, near draining ditches or gullies, the risk may be larger as lens thickness decreases significantly in their vicinity.

Based on numerical models and available spatially distributed data from different sources, a relatively straightforward data assimilation is possible towards the vulnerability of fresh water lenses to temporarily disappear. Such an assessment was done for the Dutch coastal region, and this may provide a basis for later, more detailed predictions.

If the shallowest groundwater becomes brackish or saline, this can cause the root zone to become saline due to capillary rise of marginal water. With simulations that account for erratic aspects of weather, notably rainfall, it is possible to investigate the root zone salinity as a function of different factors such as vegetation or crop, root zone thickness, groundwater depth, and climate. Typically, this leads to a salt concentration that fluctuates much as a function of time. To predict which concentrations in root zone develop on the longer term, two very simple approximations (7) and (8) are presented that reproduce the main features obtained with detailed numerical simulations pretty well. Accordingly, the concept of Leaching Requirement, that has proven its use for practical soil water and salinity management during the last 7 decades, has been extended to more complex situations. However, despite the promise of the good agreement between numerical simulations and these approximations, it is necessary to confirm the applicability with experimental evidence. If that leads to favourable results, a very useful management tool is the result.

Acknowledgments This research was funded by the Dutch Knowledge for Climate Program, Theme 2 Fresh Water Availability as well as the program WaterNexus, funded by the Technology Foundation of the Netherlands STW/NWO. 
Open Access This article is distributed under the terms of the Creative Commons Attribution 4.0 International License (http://creativecommons.org/licenses/by/4.0/), which permits unrestricted use, distribution, and reproduction in any medium, provided you give appropriate credit to the original author(s) and the source, provide a link to the Creative Commons license, and indicate if changes were made.

\section{References}

Allison LE (1964) Salinity in relation to irrigation. Adv Agron 16:139-180

Badon-Ghijben W (1888) Nota in verband met de voorgenomen putboring nabij Amsterdam. Tijdschr Van K Inst Van Ing 5:8-22

Bresler E, MacNeal B, Carter D (1982) Saline and sodic soils: principles-dynamics-modeling. Springer Verlag, New York

Cendón DI, Larsen JR, Jones BG et al (2010) Freshwater recharge into a shallow saline groundwater system, Cooper Creek floodplain, Queensland, Australia. J Hydrol 392:150-163

Cirkel DG, Van Beek C, Witte JPM, Van der Zee S (2014) Sulphate reduction and calcite precipitation in relation to internal eutrophication of groundwater fed alkaline fens. Biogeochemistry 117:375-393

Cirkel DG, van der Zee S, Meeussen JCL (2015) Front spreading with nonlinear sorption for oscillating flow. Water Resour Res 51:2986-2993

De Lange WJ, Prinsen GF, Hoogewoud JC et al (2014) An operational, multi-scale, multi-model system for consensus-based, integrated water management and policy analysis: the Netherlands hydrological instrument. Environ Model Softw 59:98-108. doi:10.1016/j.envsoft.2014.05.009

De Louw PGB, Eeman S, Siemon B et al (2011) Shallow rainwater lenses in deltaic areas with saline seepage. Hydrol Earth Syst Sci 15:3659-3678. doi:10.5194/hess-15-3659-2011

De Louw PGB, Eeman S, Oude Essink GHP et al (2013) Rainwater lens dynamics and mixing between infiltrating rainwater and upward saline groundwater seepage beneath a tile-drained agricultural field. J Hydrol 501:133-145. doi:10.1016/j.jhydrol.2013.07.026

de Wit CT (1958) Transpiration and crop yields. Instituut voor Biologisch en Scheikundig Onderzoek van Landbouwgewassen, Wageningen

Eeman S, Leijnse A, Raats PAC, Van Der Zee SEATM (2011) Analysis of the thickness of a fresh water lens and of the transition zone between this lens and upwelling saline water. Adv Water Resour 34:291-302. doi:10. 1016/j.advwatres.2010.12.001

Eeman S, Van Der Zee SEATM, Leijnse A et al (2012) Response to recharge variation of thin rainwater lenses and their mixing zone with underlying saline groundwater. Hydrol Earth Syst Sci 16:3535-3549. doi:10. 5194/hess-16-3535-2012

Fetter CW (1972) Position of the saline water interface beneath oceanic islands. Water Resour Res 8:1307-1315

Grattan SR, Grieve CM (1992) Mineral element acquisition and growth response of plants grown in saline environments. Agric Ecosyst Environ 38:275-300. doi:10.1016/0167-8809(92)90151-Z

Haasnoot M, Vermulst JAPH, Middelkoop H (1999) Impact of climate change and land subsidence on the water systems in the Netherlands. RIZA, Lelystad, the Netherlands

Herzberg A (1901) Die Wasserversorgung einiger Nordseebäder. Ztg Gasbeleucht Wasserversorgung 44: $815-819$

Javaux M, Schröder T, Vanderborght J, Vereecken H (2008) Use of a three-dimensional detailed modeling approach for predicting root water uptake. Vadose Zone J 7:1079-1088

Jolly ID, Narayan KA, Armstrong D, Walker GR (1998) The impact of flooding on modelling salt transport processes to streams. Environ Model Softw 13:87-104. doi:10.1016/S1364-8152(98)00003-6

KNMI (2014) KNMI Klimaatscenarios. http://www.klimaatscenarios.nl

Kuhlmann A, Neuweiler I, Zee S, Helmig R (2012) Influence of soil structure and root water uptake strategy on unsaturated flow in heterogeneous media. Water Resour Res 48. doi:10.1029/2011WR010651

Maas K (2007) Influence of climate change on a Ghijben-Herzberg lens. J Hydrol 347:223-228. doi:10.1016/j. jhydrol.2007.09.020

Maas E, Hoffman G (1977) Crop salt tolerance current assessment. J Irrig Drain Div 103:115-134

Martinez ML, Psuty NP (2008) Coastal dunes ecology and conservation. Springer, Ecological

Munns R, Tester M (2008) Mechanisms of salinity tolerance. Annu Rev Plant Biol 59:651-681. doi:10.1146/ annurev.arplant.59.032607.092911

Oude Essink GHP, Van Baaren ES, De Louw PGB (2010) Effects of climate change on coastal groundwater systems: a modeling study in the Netherlands. Water Resour Res 46:1-16. doi:10. 1029/2009WR008719

Parida AK, Das AB (2005) Salt tolerance and salinity effects on plants: a review. Ecotoxicol Environ Saf 60:324 349. doi:10.1016/j.ecoenv.2004.06.010 
Richards LA, Allison LE, Bernstein L et al (1954) Diagnosis and improvement of saline and alkali soils, agric. Handbook vol 60. USDA, Washington DC

Rodriguez-Iturbe I, Porporato A (2004) Ecohydrology of water-controlled ecosystems: soil moisture and plant dynamics. Cambridge University Press, Cambridge

Rozema J, Flowers T (2008) Crops for a salinized world. Science (80-) 322:1478-1480

Schinas S, Rowell DL (1977) Lime-induced chlorosis. J Soil Sci 28:351-368. doi:10.1111/j.1365-2389.1977. tb02243.x

Shah SHH, Vervoort RW, Suweis S et al (2011) Stochastic modeling of salt accumulation in the root zone due to capillary flux from brackish groundwater. Water Resour Res 47:W09506. doi:10.1029/2010WR009790

Suweis S, Rinaldo A, der Zee SEATM et al (2010) Stochastic modeling of soil salinity. Geophys Res Lett 37:n/an/a. doi:10.1029/2010GL042495

Szabolcs I (1989) Salt affected soils. CRC Press, Boca Raton

Tanji KK, Kielen NC (2002) Agricultural drainage water management in arid and semi-arid areas. FAO

Thunqvist E (2004) Regional increase of mean chloride concentration in water due to the application of deicing salt. Sci Total Environ 325:29-37. doi:10.1016/j.scitotenv.2003.11.020

Toth T (2008) Salt-affected soils in Hungary. In: Crescimanno G (ed) Needs and priorities for research and education in biotechnology applied to emerging environmental challenges in SEE countries: workshop proceedings. UNESCO-BRESCE, Venice, pp 75-81

Underwood MR, Peterson FL, Voss CI (1992) Groundwater lens dynamics of Atoll Islands. Water Resour Res 28:2889-2902. doi:10.1029/92WR01723

Van Der Veer P (1977) Analytical solution for steady interface flow in a coastal aquifer involving a phreatic surface with precipitation. J Hydrol 34:1-11. doi:10.1016/0022-1694(77)90058-0

van der Zee SEATM, Shah SHH, Vervoort RW (2014) Root zone salinity and sodicity under seasonal rainfall due to feedback of decreasing hydraulic conductivity. Water Resour Res 50:9432-9446. doi:10.1002/ 2013WR015208

Vandenbohede A, Mollema PN, Greggio N, Antonellini M (2014) Seasonal dynamic of a shallow freshwater lens due to irrigation in the coastal plain of Ravenna, Italy. Hydrogeol J 22:893-909. doi:10.1007/s10040-0141099-Z

Vervoort RW, van der Zee SEATM (2008) Simulating the effect of capillary flux on the soil water balance in a stochastic ecohydrological framework. Water Resour Res 44:n/a-n/a. doi:10.1029/2008WR006889

Vos PPC (2015) Origin of the Dutch coastal landscapes. Utrecht University

Young ME, Macumber PG, Watts MD, Al-Toqy N (2004) Electromagnetic detection of deep freshwater lenses in a hyper-arid limestone terrain. J Appl Geophys 57:43-61. doi:10.1016/j.jappgeo.2004.09.002 